\title{
BENEFICIAL EFFECT OF BROMOCRIPTINE ON HIGH FAT DIET-INDUCED BODY WEIGHT GAIN, ADIPOSITY AND BIOCHEMICAL ANOMALIES IN WISTAR RATS
}

\author{
AMIT GOYAL ${ }^{1,2 *}$, ANJOO KAMBOJ ${ }^{1}$ \\ ${ }^{1}$ Department of Pharmacology, Chandigarh College of Pharmacy, Landran, Mohali - 140110, Punjab, India. ${ }^{2}$ Department of Pharmaceutical \\ Sciences, I. K. Gujral Punjab Technical University, Jalandhar, India. Email: cgc.ccp.ag@gmail.com
}

Received: 16 February 2017, Revised and Accepted: 01 April 2017

\section{ABSTRACT}

Objectives: Dopamine plays a critical role in various vital functions, including hormonal regulation, reward, emotions, and food intake. It affects on the multiple aspects of food intake that include food selection, satiety, and energy expenditure. Dopamine D2 receptors (D2R) were found to be lower in several brain regions in both obese experimental animals and humans, and it has been observed that dopamine D2 agonist bromocriptine (BC) can exert favorable metabolic changes in seasonal obesity. The aim of this study was to investigate the beneficial effect of chronic administration of BC a central dopamine receptor agonist on body weight gain, adiposity, and biochemical anomalies in rats.

Methods: In this study, chronic administration of BC (2.5 and $5 \mathrm{mg} / \mathrm{kg} /$ day, i.p) a dopamine agonist for 8 weeks along with high-fat diet (HFD) to the obese rats which were pretreated with HFD feeding for 8 weeks on the various parameters of obesity were analyzed. The effects of these treatments on body weight, feed intake (kcal), weight and size of fat pads, levels of serum glucose, triglycerides (TG), total cholesterol (TC), high-density lipoproteins (HDL), and low-density lipoprotein were analyzed.

Results: Treatment with BC (2.5 and $5 \mathrm{mg} / \mathrm{kg} /$ day, i.p) produced significant dose-dependent decrease $(\mathrm{p}<0.05)$ in body weight gain, feed intake (kcal), weight and size of fat pads, levels of serum glucose, TG, TC, and low-density lipoproteins as compared to HFD group. Moreover, the level of serum HDL was increased as compared to HFD group. BC a dopamine receptor agonist positively modulate the parameters of obesity, and the effect was comparable to orlistat, a well-reported drug for obesity.

Conclusion: In conclusion, the study demonstrates that BC ameliorated established obesity and associated biochemical consequences

Keywords: Obesity, Bromocriptine, High-fat diet, Dopamine.

(C) 2017 The Authors. Published by Innovare Academic Sciences Pvt Ltd. This is an open access article under the CC BY license (http://creativecommons. org/licenses/by/4. 0/) DOI: http://dx.doi.org/10.22159/ajpcr.2017.v10i6.17843

\section{INTRODUCTION}

Obesity has become a serious and rising public health problem worldwide, affecting people across all ages, sex, ethnicities and races and its prevalence has been increasing at an alarming rate [1]. It is no more viewed as a cosmetic issue, but it becomes a potential risk factor of various comorbidities, such as type 2 diabetes, cardiovascular morbidity, and cancer [2,3]. Excessive fat accumulation in the body not only adversely affect on health but also impaired the quality of life, and it presents a significant challenge to future health-care budgets [4,5]. The psychological consequences are also severe and include body image disparagement and among the severely obese, depression [6-8]. Obesity is an imbalance between energy intake and expenditure [9], i.e., more food is consumed than utilized, leading to excess fat stores being laid down. Freely available high-calorie food, sedentary lifestyle and many environmental factors predispose individuals to gain weight. Genetic factors also contribute to this imbalance [10]. In the severely obese, surgical intervention may be necessary. An alternative approach is to develop therapeutic agents that can either reduce food consumption or increase energy utilization. Despite intensive research on obesity pathogenesis, an effective therapeutic strategy to treat and cure obesity is still lacking. At present, only a few FDA-approved antiobesity drugs such as orlistat, lorcaserin, phentermine-topiramate, and naltrexone-bupropion are available in the market, but they have considerable side effects [11]. Exciting studies in past decades have established the importance of neural pathway in the hypothalamus in the regulation of body weight homeostasis. Recent research significantly expanded the list of neurotransmitters involved in body weight regulating neural pathways [12]. Understanding the function of neurotransmitters released from key neurons for energy balance regulation is essential for delineating neural pathways and eventually for designing effective therapeutic drugs against the obesity epidemic. Considerable efforts have been devoted to the development of weight control medications that target neurotransmitters in the brain that regulate food intake [13]. Several neurotransmitters (dopamine, GABA, norepinephrine, and serotonin), as well as peptides and amino acids, are involved in the regulation of food intake [14]. The cerebral mechanisms underlying the behaviors that lead to pathological overeating and obesity are poorly understood [15]. Dopamine, a neurotransmitter in the mammalian brain plays, a critical role in various vital functions, including hormonal regulation, reward, emotions, and food intake. It affects on the multiple aspects of food intake that include food selection, satiety, and energy expenditure $[16,17]$. Several lines of research indicate that abnormal dopaminergic neurotransmission could be involved in pathophysiological processes leading to obesity. Most of these studies are focused on the hypothalamic dopamine transmission that is believed to play a pivotal role in the guidance of fuel flux and energy homeostasis [18]. In general, these investigations have indicated a decreased dopaminergic signaling in obese subjects. For example, dopamine D2 receptors (D2R) were found to be lower in several brain regions in both obese experimental animals and humans, and it has been observed that dopamine D2 agonist bromocriptine (BC) can exert favorable metabolic changes in seasonal obesity [19]. The aim of this study was to investigate the beneficial effect of chronic administration of $\mathrm{BC}$ a central dopamine receptor agonist on body weight gain, adiposity, and biochemical anomalies in rats. 


\section{METHODS}

\section{Drugs and chemicals}

Casein (Modern Diary, New Karnal, India) and cholesterol (Thomas Baker, Mumbai, India) were used to prepare high-fat diet (HFD). BC was purchased from local market. Orlistat (Sigma-Aldrich) is (S)-2formylamino-4-methyl-pentanoic acid (S)-1-[[(2S,3S)-3-hexyl-4-oxo-2oxetanyl]methyl]dodecyl ester. All the drugs were dissolved in dimethyl sulfoxide (DMSO; 10\%,v/v). The estimation kits for serum glucose, cholesterol, triglycerides (TG), and high-density lipoproteins (HDL) were obtained from (Reckon Diagnostics [P] Ltd. Vadodara, India). All other chemicals used in this study were of analytical grade. All drug solutions were freshly prepared before use.

\section{HFD-induced obesity}

Experimental obesity was induced by feeding HFD (containing; powdered normal chow [NC], $365 \mathrm{~g}$; lard, $310 \mathrm{~g}$; casein, $250 \mathrm{~g}$; cholesterol, $10 \mathrm{~g}$; vitamin mix and mineral mix, $60 \mathrm{~g}$; dl-methionine, $03 \mathrm{~g}$; yeast powder, $01 \mathrm{~g}$; $\mathrm{NaCl}, 01 \mathrm{~g}$ were added to make $1.0 \mathrm{~kg}$ of diet) to rats [20]. The HFD contained $5.33 \mathrm{Kcal} / \mathrm{g}$ while the NC contains $3.80 \mathrm{Kcal} / \mathrm{g}$. This diet provides $68 \%$ energy as carbohydrate, $20 \%$ as protein and $12 \%$ as fat to produce obesity in rats while as NC provides $65 \%$ of energy as carbohydrate, $20 \%$ as protein, and $4 \%$ as fat [21].

\section{Animal treatment}

Male Wistar rats of 7-8 weeks of age were procured from the animal facility of the Institute. The animals were housed in polypropylene cages (two rats/cage) and maintained under controlled room temperature $\left(25 \pm 2^{\circ} \mathrm{C}\right)$ with $12: 12 \mathrm{hrs}$ light and dark cycle. The guidelines of Committee for the Purpose of Control and Supervision of Experiments on Animals (CPCSEA), Government of India were followed, and prior permission was sought from the Institutional Animal Ethics Committee for conducting the study. Animals were fed with NC or HFD for 8 weeks. Animals were divided into different groups and each group contained 6 animals. Animals fed on NC were continued on the same diet for further 8 weeks and were assigned as Group 1. HFD fed animals randomized on the basis of their body weight and divided into different 5 groups (Group 2-6), and these groups were continued on HFD for another 8 weeks. Group 2 was not given any treatment and assigned as HFD control. Group 3 was given DMSO $1 \mathrm{ml} / \mathrm{kg}$ day $^{-1}$, i.p [22] and assigned as vehicle control. Group 4 was given orlistat $30 \mathrm{mg} / \mathrm{kg} \mathrm{day}^{-1}$, p.o. [21] and assigned as a standard control. Groups 5 and 6 were given BC 2.5 and $5 \mathrm{mg} / \mathrm{kg} \mathrm{day}^{-1}$, i.p, respectively [23]. All the animals had free access to water, and the animals were inspected daily. Food intake and body weight were measured twice weekly. At the end of the stipulated period, blood for various biochemical parameters was obtained by retro-orbital puncture under light ether anesthesia, and the animals were sacrificed by cervical dislocation. The blood was collected into tubes, serum separated, and analyzed on the same day. The epididymal, mesenteric, and retroperitoneal white adipose tissue (WAT) were dissected, cleaned of, weighed and stored in $10 \%$ buffered formalin solution for histological analysis. Lee index [24], i.e., (Body Wt in g) $1 / 3 /$ (ano-nasal length in $\mathrm{cm}$ ) an index of obesity, was calculated at the end of the experiment.

\section{Histological analysis and morphometry}

Epididymal adipose tissue was fixed in $10 \%$ formalin and then embedded with paraffin. Tissue sections $(10 \mu \mathrm{m})$ were cut and mounted on microscope slides. After being air-dried, they were stained with hematoxylin and eosin and photographed at $\times 100$ magnification. At least two fields per slice and six slices per fat mass were analyzed for the purpose of quantifying adipocyte size.

\section{Measurements}

Serum glucose, TG, total cholesterol (TC), and HDL cholesterol concentrations were measured using commercially available kits.

\section{Statistical analysis}

All values are expressed as mean \pm standard deviation (SD). The significance of the differences between the means of various groups was established by one-way ANOVA with a Tukey's post hoc test using the GraphPad Prism 4 software. The $p<0.05$ was considered to be statistically significant.

\section{RESULTS}

Administration of HFD for 8 weeks significantly $(\mathrm{p}<0.05)$ increased body weight of animals then the age-matched normal control rats, and there was no significant difference of body weights of animals between the various treatment groups before initiation of treatment (Table 1).

Effect of various pharmacological interventions on body weight, adipose tissue weight, and lee index

Obese rats after 16 weeks of HFD feeding had significantly increased body weight and total fat content then the age-matched normal control rats (Fig. 1a and b). Lee index was also significantly increased in obese rats as compared to normal rats (Fig. 1c). However, treatment with BC $(2.5$ and $5 \mathrm{mg} / \mathrm{kg})$ from 9 to 16 weeks attenuated HFD induced increase in body weight, adipose pads weight, and lee index. Administration of DMSO (10\% v/v DMSO, $1 \mathrm{ml} / \mathrm{kg}$ ) from 9 to 16 weeks did not affect HFD induced increase in body weight, adipose pads weight, and lee index. Administration of orlistat $(30 \mathrm{mg} / \mathrm{kg}$ ) a standard drug of obesity from 9 to 16 weeks produced a significant reduction in body weight gain, adipose pads weight, and lee index in obese rats (Table 2).

\section{Effect of various pharmacological interventions on biochemical parameters}

Obese rats after 16 weeks of HFD feeding had higher glucose, TG, and TC level as compared to the age-matched normal control rats (Fig. $1 \mathrm{~d}-\mathrm{f}$ ). However, treatment with BC (2.5 and $5 \mathrm{mg} / \mathrm{kg})$ from 9 to 16 weeks attenuated HFD induced hyperglycemia, hypertriglyceridemia, and hypercholesterolemia. Administration of DMSO (10\% v/v DMSO, $1 \mathrm{ml} /$ $\mathrm{kg}$ ) from 9 to 16 weeks did not affect HFD induced hyperglycemia, hypertriglyceridemia, and hypercholesterolemia. Administration of orlistat $(30 \mathrm{mg} / \mathrm{kg})$ a standard drug of obesity from 9 to 16 weeks produced a significant reduction in the level of glucose, TG, and TC in obese rats (Table 2)

Effect of various pharmacological interventions on adipocyte size Histological examination of epididymal WAT revealed that HFD fed rats had markedly increased adipocyte size than did NC - fed rats. BC $(2.5$ and $5 \mathrm{mg} / \mathrm{kg}$ ) or orlistat $(30 \mathrm{mg} / \mathrm{kg}$ ) markedly suppressed epididymal adipocyte size compared to HFD fed rats. While DMSO (10\% v/v DMSO, $1 \mathrm{ml} / \mathrm{kg}$ ) did not suppressed these adipose tissue size as compared to HFD rats (Fig. 2).

Table 1: Body weight of animals at 0 week, at the end of $8^{\text {th }}$ week and at the end of $16^{\text {th }}$ week

\begin{tabular}{|c|c|c|c|}
\hline Groups & Initial body weight & Body weight at the end of $8^{\text {th }}$ week & Body weight at the end of $16^{\text {th }}$ week \\
\hline NC & $222 \pm 9.3$ & $242 \pm 13.5$ & $282 \pm 17.8$ \\
\hline OHFD-C & $233 \pm 8.1$ & $312.1 \pm 5.03^{\mathrm{a}}$ & $399 \pm 16.2^{\mathrm{a}}$ \\
\hline Vehicle control (10\% v/v DMSO, $1 \mathrm{ml} / \mathrm{kg})$ & $234.3 \pm 7.9$ & $316.3 \pm 8.5^{\mathrm{a}}$ & $397 \pm 13^{\mathrm{a}}$ \\
\hline Orlistat $(30 \mathrm{mg} / \mathrm{kg})$ & $236 \pm 11.9$ & $309.5 \pm 13.6^{a}$ & $299 \pm 14.6^{b}$ \\
\hline Bromocriptine (2.5 mg/kg) & $229 \pm 12.8$ & $318 \pm 5.7^{\mathrm{b}}$ & $324.5 \pm 11.6^{\mathrm{b}}$ \\
\hline Bromocriptine ( $5 \mathrm{mg} / \mathrm{kg})$ & $228.6 \pm 10.8$ & $311 \pm 13.7^{\mathrm{b}}$ & $305.3 \pm 13.29^{\mathrm{b}}$ \\
\hline
\end{tabular}

All values are expressed as mean \pm SD, $n=6$, one-way ANOVA followed by Tukey's multiple range test. DMSO: Dimethyl sulfoxide. ${ }^{a} p<0.05$ versus NC: Normal control,

${ }^{\mathrm{b}} \mathrm{p}<0.05$ versus OHFD-C: Obese high-fat diet control, SD: Standard deviation 


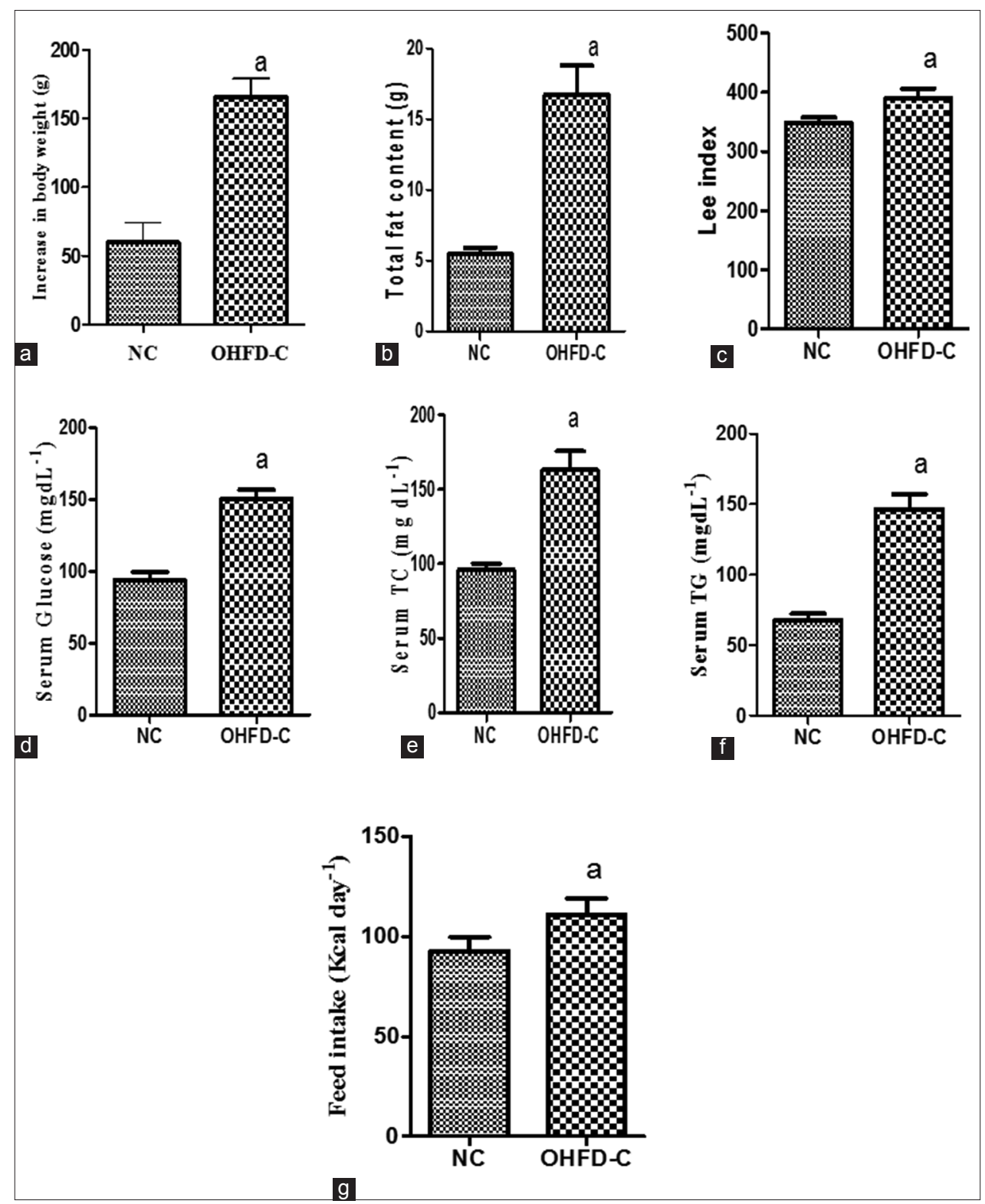

Fig. 1: Effect of high-fat diet (HFD) on various parameters in obese rats continued on HFD for further 8 weeks: (a) Increase in body weight, (b) total fat content, (c) Lee index, (d) serum glucose, (e) serum total cholesterol (TC), (f) serum triglycerides (TG), (g) daily feed intake in Kcal. All values are expressed as Mean \pm Standard deviation, $n=6$, one-way ANOVA followed by Tukey's multiple range test. TG, TC, ${ }^{\mathrm{a}} \mathrm{p}<0.05$ versus normal control

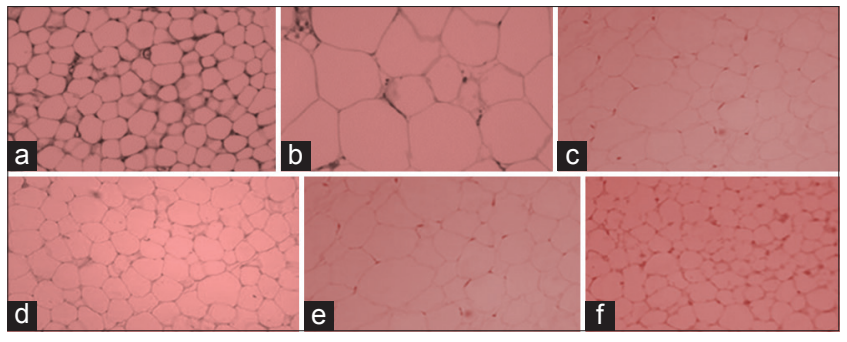

Fig. 2: Effect of various pharmacological interventions on adipocyte size: (a) Adipocyte size of normal control animals,

(b) adipocyte size of obese high-fat diet control animals,

(c) adipocyte size of vehicle control animals, (d) adipocyte size of standard control animals, (e) adipocyte size of animals given $\mathrm{BC} 2.5 \mathrm{mg} / \mathrm{kg} \mathrm{day}^{-1}$, (f) adipocyte size of animals given BC $5 \mathrm{mg} / \mathrm{kg} \mathrm{day}^{-1}$
Effect of various pharmacological interventions on daily feed intake (Kcal)

In HFD model, a significant increase $(\mathrm{p}<0.05)$ in feed consumption (Kcal) was observed as compared to NC-fed rats (Fig. 1g). Orlistat $(30 \mathrm{mg} / \mathrm{kg}$ ) which was standard control in this study significantly decreases the feed consumption as compared to HFD fed rats. Administration of DMSO (10\% v/v DMSO, $1 \mathrm{ml} / \mathrm{kg}$ ) from 9 to 16 weeks did not affect feed consumption of animals as compared to HFD fed rats. The food intake was significantly decreased by the administration of BC ( 2.5 and $5 \mathrm{mg} / \mathrm{kg}$ ) from 9 to 16 weeks (Table 2).

\section{DISCUSSION}

In this study, experimental obesity was developed by long-term HFD treatment. HFD have been previously reported to increase energy intake and cause obesity in humans as well as animals $[25,26]$. The body weight gain observed in this study is consistent with studies in 
Table 2: Effect of various Pharmacological interventions on body weight, adipose tissue weight, and various biochemical parameters in obese rats continued on high-fat diet for further 8 weeks

\begin{tabular}{|c|c|c|c|c|c|c|}
\hline \multirow[t]{2}{*}{ Parameters } & \multirow[t]{2}{*}{ NC } & \multirow[t]{2}{*}{ OHFD-C } & \multirow{2}{*}{$\begin{array}{l}\text { Vehicle control }(10 \% \mathrm{v} / \mathrm{v} \text { DMSO, } \\
1 \mathrm{ml} / \mathrm{kg})\end{array}$} & \multirow[t]{2}{*}{ Orlistat $(30 \mathrm{mg} / \mathrm{kg})$} & \multicolumn{2}{|c|}{ Bromocriptine (mg/kg) } \\
\hline & & & & & 2.5 & 5 \\
\hline Initial body weight (g) & $222 \pm 9.3$ & $233 \pm 8.1$ & $234.3 \pm 7.9$ & $236 \pm 11.9$ & $229 \pm 12.8$ & $228.6 \pm 10.8$ \\
\hline Final body weight (g) & $282 \pm 17.8$ & $399 \pm 16.2^{\mathrm{a}}$ & $397 \pm 13^{\mathrm{a}}$ & $299 \pm 14.6^{\mathrm{b}}$ & $324.5 \pm 11.6^{\mathrm{b}}$ & $305.3 \pm 13.29^{\mathrm{b}}$ \\
\hline Lee index & $348 \pm 9.2$ & $389 \pm 16.7^{\mathrm{a}}$ & $394.19 \pm 14^{\mathrm{a}}$ & $361 \pm 21.4^{\mathrm{b}}$ & $379.3 \pm 16.9^{b}$ & $355.45 \pm 9.7^{\mathrm{b}}$ \\
\hline Feed intake Kcal day ${ }^{-1}$ & $92 \pm 7.1$ & $111 \pm 7.8^{\mathrm{a}}$ & $110.15 \pm 10.4^{\mathrm{a}}$ & $85 \pm 12.8^{b}$ & $104.4 \pm 9.9^{\mathrm{b}}$ & $98.6 \pm 6.3^{b}$ \\
\hline Epididymal fat & $1.75 \pm 0.23$ & $5.25 \pm 0.94^{\mathrm{a}}$ & $5.26 \pm 0.9^{a}$ & $1.90 \pm 0.32^{\mathrm{b}}$ & $2.1 \pm 0.15^{\mathrm{b}}$ & $1.98 \pm 0.16^{\mathrm{b}}$ \\
\hline Retroperitoneal fat & $1.56 \pm 0.29$ & $5.8 \pm 0.87^{\mathrm{a}}$ & $5.78 \pm 0.89^{a}$ & $1.96 \pm 0.28^{b}$ & $2.4 \pm 0.52^{\mathrm{b}}$ & $1.9 \pm 0.46^{\mathrm{b}}$ \\
\hline Mesenteric fat & $2.1 \pm 0.19$ & $5.6 \pm 0.95^{\mathrm{a}}$ & $5.71 \pm 0.74^{\mathrm{a}}$ & $2.6 \pm 0.38^{b}$ & $2.9 \pm 0.67^{b}$ & $1.86 \pm 0.22^{\mathrm{b}}$ \\
\hline Glucose (mg/dL) & $94 \pm 5.5$ & $150.5 \pm 6.47^{a}$ & $149.6 \pm 5.8^{\mathrm{a}}$ & $96.7 \pm 4.09^{b}$ & $101.1 \pm 5.9^{\mathrm{b}}$ & $93.8 \pm 2.7^{b}$ \\
\hline $\mathrm{TG}(\mathrm{mg} / \mathrm{dL})$ & $67.7 \pm 4.4$ & $146.5 \pm 10.65^{a}$ & $145.5 \pm 10.4^{\mathrm{a}}$ & $71 \pm 5.17^{\mathrm{b}}$ & $80 \pm 4.2^{\mathrm{b}}$ & $69.3 \pm 3.6^{\mathrm{b}}$ \\
\hline $\mathrm{TC}(\mathrm{mg} / \mathrm{dL})$ & $95.9 \pm 4.1$ & $163 \pm 12.64^{\mathrm{a}}$ & $162.6 \pm 12.8^{\mathrm{a}}$ & $95.8 \pm 5.19^{b}$ & $100.8 \pm 4.8^{\mathrm{b}}$ & $91.3 \pm 2.7^{b}$ \\
\hline LDL (mg/dL) & $49.8 \pm 5.7$ & $110.3 \pm 12.54^{\mathrm{a}}$ & $110.9 \pm 11.5^{\mathrm{a}}$ & $49.4 \pm 7.06^{\mathrm{b}}$ & $54.6 \pm 4.4^{\mathrm{b}}$ & $43.63 \pm 4.74^{\mathrm{b}}$ \\
\hline VLDL (mg/dL) & $13.5 \pm 0.89$ & $29.3 \pm 2.13^{\mathrm{a}}$ & $29.1 \pm 2^{\mathrm{a}}$ & $14.2 \pm 1.03^{\mathrm{b}}$ & $16 \pm 4.2^{\mathrm{b}}$ & $13.6 \pm 0.73^{\mathrm{b}}$ \\
\hline HDL (mg/dL) & $32.5 \pm 2.19$ & $23.3 \pm 2.94^{\mathrm{a}}$ & $22.6 \pm 1.75^{\mathrm{a}}$ & $32.1 \pm 2.85^{\mathrm{b}}$ & $30.1 \pm 1.9^{b}$ & $33.8 \pm 2.5^{\mathrm{b}}$ \\
\hline
\end{tabular}

All values are expressed as mean \pm SD, $n=6$, one-way ANOVA followed by Tukey’s multiple range test. DMSO: Dimethyl sulfoxide, TG: Triglycerides, TC: Total cholesterol, LDL: Low-density lipoproteins, VLDL: Very low-density lipoproteins, HDL: High-density lipoproteins. ${ }^{a}$ p $<0.05$ versus NC: Normal control, ${ }^{b}$ p $<0.05$ versus OHFD-C: Obese high-fat diet control, SD: Standard deviation

animal models, suggesting that exposure to high concentrations of carbohydrates or HFD contribute to the development of overweight or obesity [27]. Notably, metabolic disturbance results in elevation of plasma lipids [28] which is characterized by elevated TC, TG levels, low-density lipoprotein cholesterol (LDL-C) levels, and decreased serum HDL-C [29]. Further, feeding with HFD caused hyperglycemia in rats [30]. Therefore, the serum lipid levels (TC, LDL, very LDL [VLDL], HDL, and TG) and glucose levels were estimated in this study as the marker of hyperlipidemia and hyperglycemia.

There is a relationship between HFD intake and neurotransmitter concentration in the rat brain [31]. Various reports showed that there is a lower dopamine D2R availability in the striatum of obese individuals than in normal individuals [15]. Earlier findings showed that the administration of dopamine agonists normalizes body weight in genetically obese mice [32]. BC is a D2R agonist shown to reduce BMI in individuals with prolactinomas [33]. Hence, this study was undertaken to examine the effect of BC in HFD induced obesity by peripheral administration of $\mathrm{BC}$ in two different doses, i.e., low and high dose. Our data demonstrated that in HFD rats, (1) high dose of BC treatment significantly reduced food intake, lee's index, and body weight increase, (2) the weight of WAT was significantly decreased and the biochemical levels of glucose, TG, TC, LDL, and VLDL was significantly improved by high dose of $\mathrm{BC}$ treatment as compared to HFD rats. The high dose of $\mathrm{BC}$ was found to be more effective as compared to its low dose this result gives the evidence that $\mathrm{BC}$ prevents the progression of obesity from predisposed factors.

These findings suggested that reduction in food intake may be due to $\mathrm{D} 2 \mathrm{R}$ agonism by BC. The decreased $\mathrm{D} 2 \mathrm{R}$ in obese individuals perpetuate pathological eating as a means to compensate for the decreased activation of reward circuits, which are modulated by dopamine [34]. This may reflect direct hypothalamic effects that result in decreased appetite and/or be the consequence of increased sensitivity toward reward induced by D2R agonism, thereby reducing the need for food intake. Indeed, recent study reported that BC administration led to an increase in D2R binding in the lateral hypothalamus in obese leptin receptor deficient Zucker rats [35]. This increase in D2R binding after $\mathrm{BC}$ treatment was also observed in other regions such as the striatum, nucleus accumbens shell/core, and ventral tegmental area and was paralleled by decreases in food intake and adiposity. A previous study conducted using N-0437, a selective D2R agonist also supported the reduction in food intake induced by D2R agonism [36].

In this investigation, it has been observed that administration of BC in the low and high dose for 8 weeks to the obese rats which were pretreated with HFD feeding for 8 weeks positively alters the various other parameters of obesity. The BC showed their actions mainly due to decreased feed intake. Hence, it has been observed that BC plays major beneficial role in obesity. Although in this study we have focused on dopamine, it is important to point out that the regulation of body weight is complex and involves other physiological mechanisms and other neurotransmitters [14].

The results from this study have implications for the treatment of obesity since they would suggest that strategies aimed at improving dopamine function might be beneficial in the treatment of obese individuals. In animal models, exercise has been found to increase dopamine release, [37] and to raise D2R [38]. Further research to identify treatment approaches that enhance the function of the dopamine system as a means to promote long-term maintenance of weight control is warranted. This data demonstrate that D2R agonist has the potential to work by reduce food intake in obese rats. Hence, it has been observed that $\mathrm{BC}$ plays major beneficial role in obesity; also, this study has provided a rational pharmacological basis for the use of $\mathrm{BC}$ in obesity.

\section{CONCLUSION}

In conclusion, this data provide the first evidence that $\mathrm{BC}$ positively alters the various parameters of obesity. BC shows these affects by acting on dopaminergic receptor in the brain, it mainly decreases food intake in obese rats. These findings suggest that dopamine agonist BC could be new therapeutic reagents for obesity.

\section{ACKNOWLEDGMENT}

We are very thankful to Chandigarh College of Pharmacy, Landran and IKGPTU Jalandhar, for their support.

\section{REFERENCES}

1. Verma RK, Paraidathathu T. Herbal medicines used in the traditional Indian medicinal system as a therapeutic treatment option for overweight and obesity management: A review. Int J Pharm Pharm Sci 2014;6:40-7

2. McIntyre AM. Burden of illness review of obesity: Are the true costs realised? J R Soc Health 1998;118(2):76-84.

3. Kopelman P. Health risks associated with overweight and obesity. Obes Rev 2007;8 Suppl 1:13-7.

4. Haslam DW, James WP. Obesity. Lancet 2005;366(9492):1197-209.

5. Obesity: Preventing and managing the global epidemic. Report of a WHO consultation. World Health Organ Tech Rep Ser 2000;894:i-xii, 1-253.

6. Carpenter KM, Hasin DS, Allison DB, Faith MS. Relationships between obesity and DSM-IV major depressive disorder, suicide ideation, and suicide attempts: Results from a general population study. Am J Public 
Health 2000;90(2):251-7.

7. Foster GD, Wadden TA. Psychology of obesity, weight loss, and weight regain: Clinical and research findings. In: Blackburn GL, Kanders BS, editors. Obesity: Pathophysiology, Psychology and Treatment. New York: Chapman and Hall; 1994. p. 140-66.

8. Kushner RF, Foster GD. Obesity and quality of life. Nutrition 2000;16(10):947-52

9. Khaserao S, Somani R. Evaluation of anti-obesity activity of solasodine in high fat diet-induced obesity in rat. Int J Pharm Pharm Sci 2017;9:23-9.

10. Bloom SR, Kuhajda FP, Laher I, Pi-Sunyer X, Ronnett GV, Tan TM, et al. The obesity epidemic: Pharmacological challenges. Mol Interv 2008;8(2):82-98

11. Khorassani FE, Misher A, Garris S. Past and present of antiobesity agents: Focus on monoamine modulators. Am J Health Syst Pharm 2015;72(9):697-706.

12. Xu Y, Tong Q. Expanding neurotransmitters in the hypothalamic neurocircuitry for energy balance regulation. Protein Cell 2011;2(10):800-13.

13. Bray GA, Tartaglia LA. Medicinal strategies in the treatment of obesity. Nature 2000;404(6778):672-7

14. Schwartz MW, Woods SC, Porte D Jr, Seeley RJ, Baskin DG. Central nervous system control of food intake. Nature 2000;404(6778):661-71.

15. Wang GJ, Nora DV, Jean L, Naomi RP, Christopher TW, Wei Z, et al. Brain dopamine and obesity. Lancet 2001;357:354-7.

16. Berthoud HR. Multiple neural systems controlling food intake and body weight. Neurosci Biobehav Rev 2002;26(4):393-428.

17. Kelley AE. Ventral striatal control of appetitive motivation: Role in ingestive behavior and reward-related learning. Neurosci Biobehav Rev 2004;27(8):765-76.

18. Pijl H. Reduced dopaminergic tone in hypothalamic neural circuits: Expression of a "thrifty" genotype underlying the metabolic syndrome? Eur J Pharmacol 2003;480(1-3):125-31

19. Baptista T. Body weight gain induced by antipsychotic drugs: Mechanisms and management. Acta Psychiatr Scand 1999;100(1):3-16.

20. Srinivasan K, Viswanad B, Asrat L, Kaul CL, Ramarao P. Combination of high-fat diet-fed and low-dose streptozotocin-treated rat: A model for type 2 diabetes and pharmacological screening. Pharmacol Res 2005;52(4):313-20.

21. Malik Z, Sharma PL. An ethanolic extract from licorice (Glycyrrhiza glabra) exhibit anti-obesity effects by decreasing dietary fat absorption in a high fat diet-induced obesity rat model. IJPSR 2011;2:3010-8.

22. Lin TB, Lo MJ, Huang CY, Ting H, Lee SD. GABAergic modulation of ventilatory response to acute and sustained hypoxia in obese Zucker rats. Int J Obes (Lond) 2005;29(2):188-95.

23. Brannan T, Martínez-Tica J, Di Rocco A, Yahr MD. Low and high dose bromocriptine have different effects on striatal dopamine release: An in vivo study. J Neural Transm Park Dis Dement Sect 1993;6(2):81-7.

24. Bernardis LL, Luboshitsky R, Bellinger LL, McEwen G. Nutritional studies in the weanling rat with normophagic hypothalamic obesity.
J Nutr 1982;112(7):1441-55.

25. Arçari DP, Bartchewsky W, dos Santos TW, Oliveira KA, Funck A, Pedrazzoli J, et al. Antiobesity effects of yerba maté extract (Ilex paraguariensis) in high-fat diet-induced obese mice. Obesity (Silver Spring) 2009;17(12):2127-33.

26. Prats E, Monfar M, Castellà J, Iglesias R, Alemany M. Energy intake of rats fed a cafeteria diet. Physiol Behav 1989;45(2):263-72.

27. Panchal SK, Poudyal H, Iyer A, Nazer R, Alam MA, Diwan V, et al. High-carbohydrate, high-fat diet-induced metabolic syndrome and cardiovascular remodeling in rats. J Cardiovasc Pharmacol 2011;57(5):611-24

28. Storlien LH, James DE, Burleigh KM, Chisholm DJ, Kraegen EW. Fat feeding causes widespread in vivo insulin resistance, decreased energy expenditure, and obesity in rats. Am J Physiol 1986;251:E576-83.

29. Woods SC, Seeley RJ, Rushing PA, D’Alessio D, Tso P. A controlled highfat diet induces an obese syndrome in rats. J Nutr 2003;133(4):1081-7.

30. Ikemoto S, Thompson KS, Takahashi M, Itakura H, Lane MD, Ezaki O. High fat diet-induced hyperglycemia: Prevention by low level expression of a glucose transporter (GLUT4) minigene in transgenic mice. Proc Natl Acad Sci U S A 1995;92(8):3096-9.

31. Valladolid-Acebes I, Merino B, Principato A, Fole A, Barbas C, Lorenzo MP, et al. High-fat diets induce changes in hippocampal glutamate metabolism and neurotransmission. Am J Physiol Endocrinol Metab 2012;302(4):E396-402.

32. Bina KG, Cincotta AH. Dopaminergic agonists normalize elevated hypothalamic neuropeptide $Y$ and corticotropin-releasing hormone, body weight gain, and hyperglycemia in ob/ob mice. Neuroendocrinology 2000;71(1):68-78

33. Doknic M, Pekic S, Zarkovic M, Medic-Stojanoska M, Dieguez C, Casanueva $\mathrm{F}$, et al. Dopaminergic tone and obesity: An insight from prolactinomas treated with bromocriptine. Eur J Endocrinol 2002;147(1):77-84.

34. Berridge KC, Robinson TE. What is the role of dopamine in reward: Hedonic impact, reward learning, or incentive salience? Brain Res Brain Res Rev 1998;28(3):309-69.

35. Davis LM, Michaelides M, Cheskin LJ, Moran TH, Aja S, Watkins PA, et al. Bromocriptine administration reduces hyperphagia and adiposity and differentially affects dopamine D2 receptor and transporter binding in leptin-receptor-deficient Zucker rats and rats with diet-induced obesity. Neuroendocrinology 2009;89(2):152-62

36. Clifton PG, Rusk IN, Cooper SJ. Stimulation and inhibition of food intake by the selective dopamine D2 agonist, N-0437: A meal pattern analysis. Pharmacol Biochem Behav 1989;33(1):21-6

37. Hattori S, Naoi M, Nishino H. Striatal dopamine turnover during treadmill running in the rat: Relation to the speed of running. Brain Res Bull 1994;35(1):41-9.

38. MacRae PG, Spirduso WW, Walters TJ, Farrar RP, Wilcox RE. Endurance training effects on striatal D2 dopamine receptor binding and striatal dopamine metabolites in presenescent older rats. Psychopharmacology (Berl) 1987;92(2):236-40. 